\title{
Optimization of Honey Bee Production
}

\author{
Y.O. Aderinto, A. Azagbaekwue, O. M. Bamigbola \\ Department of Mathematics, Faculty of Physical Sciences, University of Ilorin, Ilorin, Nigeria \\ M. O. Oke, A. A. Obayomi \\ Department of Mathematics, Ekiti State University, Ado-Ekiti, Nigeria \\ L. O. Salaudeen \\ Department of Mathematics, Federal University Oye-Ekiti, Nigeria \\ T. O. Aliu \\ Department of Mathematics and Statistics, Kwara State University, Molete, Nigeria.
}

\begin{abstract}
Beekeepers are faced with quite a number of challenges such as selection of fields and enhancement of honey production. In this paper crisp deterministic honey bee production model was formulated in an attempt to optimize the distribution of beehives in the apiary in order to maximize production of honey and minimize unhealthy competition among foraging bees which often arises as a result of overcrowding. The model was characterized using Weighted sum model (WSM) and Analytic Hierarchical Model (AHM). Finally the validity of the model was tested with the real life data and the results obtained shows that proper distribution of the bee hives in the apiary is important to maximize production and minimize unpleasant fields.
\end{abstract}

Keywords-Beehive, Field, Honey bee production, Mathematical Model, Optimization, Optimal spatial distribution.

\section{INTRODUCTION}

Honey bees are social insects that belong to the family of Apidae, Apis and Apis melifera and are considered to be one of the most highly developed social insects among the invertebrate animals due to their social life which involves exhibiting very well adapted collective behaviors. These social insects visit approximately two million flowers to make one pound of honey for human use, [5]. Honey bees live in colonies made of only one queen, some few drones and thousands of workers. The strength of the bee colonies basically depends on the availability of nectar and pollen which are the major needs of honey bees. Honey bee production (honey beekeeping) is the rearing of honey bee for honey and other by-products. It is the maintenance of honey bee colonies, commonly in hives, by humans which provides great potential for development in almost all countries of the world, [12], [5]. Traditional beekeeping in trees is practiced by climbing the tree. The climbing involves the use of ladder and ropes. In some parts of Southern and Central States of Nigeria, pots are kept on the ground as a means of hives in bee-keeping,[1]. In Eastern Nigeria, palm wine is used to attract bees to traditional hives. In Southern Bauchi, clay or mud hives are used to keep bees. The modern and/or scientific method of beekeeping is called Apiculture, it is the practice of honey bee rearing that combines the knowledge of the social behavior and biology of the bees with that of the environment and the use of apiary equipment to maximize honey production and output of other bee hives production, [3].

Bees play significant roles in agricultural sector as honey bees are highly needed in crop pollination leading to increase in national food production and regeneration of plant species. Honey not only tasted good but also provides important food nutrients, protein, energy and sugar which accounts for 95-99 percent of honey dry matter, [8].

A colony of honey bee is a biological unit or family that consist of three different types of bees. The Queen or mother bee which is a fertile, egg laying female, the worker bees are infertile female. The drones which are male bees are always present in the reproductive season, but may be kicked out by worker bees during dearth or food scarcity. The composition is usually one queen to 60,000 workers and about 100 drones in an average colony, [12], [15]. Bee keeping has significant role in ensuring food security because honey bee pollination cultivated crop and vegetable and enhance productivity(such as fruits, vegetable and dairy products, including ice cream),[3]. Optimization of production of honey bees is at moment paramount in the nation's economy.

Mathematical model is the general characterization of a process, object or concept in term of mathematics in order to determine behaviors in different situations,[4]. Optimization algorithm known as Honey Bee Algorithm are search methods where the goal is to find an optimal solution to a problem, in order to satisfy one or more objective functions, possibly subject to a set of constraints. Studies of social animals and social insects have resulted in a number of mathematical models and computational models of swarm intelligence. A good number of researches have been carried out on honey bee algorithm and mathematical 
models, [2], [4], [6], [10], [11], [13],[14], [18], to mention a few.

In apiculture, the use of appropriate beekeeping equipments such as Movable frame hives, Smoker, Honey bee extractor, Hive tool, Gloves, Bee Veil, Queen cage, Bee Brushes and the likes for colony inspection, management and harvesting of honey makes the practice to be quick and easy.

Determining the optimal placement of bee colonies in a large apiary can be regarded as a combinatorial problem solvable using mathematical programming tools. Formulated mixed -integer linear programs that can be used in determining the best location of beehives taking into account the preferred location of the beekeeper, number and strength of available colonies, carrying capacity of the plant clusters, maximum flight distance that the bees can travel, and spatial orientation of the apiary. Sites separated by millimeters present a different spatial problem than sites separated by kilometers. [15] present an Ideal Free Distribution Model that accounts for the effects of distance by assuming that a forager's gains gradually decrease as its distance from a site increases. [14] applied mixed integer programming in the relocation of bee colonies whenever overpopulation occurs in the apiary. [8] designed a model to determine the optimal distribution of beehives in location site such that overpopulation is minimized.

However, despite the number of researches on honey bee which most of them focused on bee algorithm and bee foraging, little or less has been done on optimization of honey bee production to enhance optimal production of honey. Hence, in this paper, the interest is to optimize honey bee distribution in apiary to improve production of honey which in turn maximize the profit and minimize cost of keeping hives in terms of feeding, labour and storage while overcrowding is avoided to reduce unhealthy competition among bees.

\section{MODEL FORMULATION}

In apiculture, the placement of beehives is essential to avoid unhealthy competition among bees. A model for identifying the optimal spatial distribution of beehives in an apiary for minimizing competition in colonies was designed. To determine the best location site for beehives, there is need to consider; the distance of the hive from the food sources and the maximum flight distance that the bee species can travel which is incorporated in the network characterizing the spatial orientation of the apiary sample as presented.

Consider the apiary network in "Fig" 1

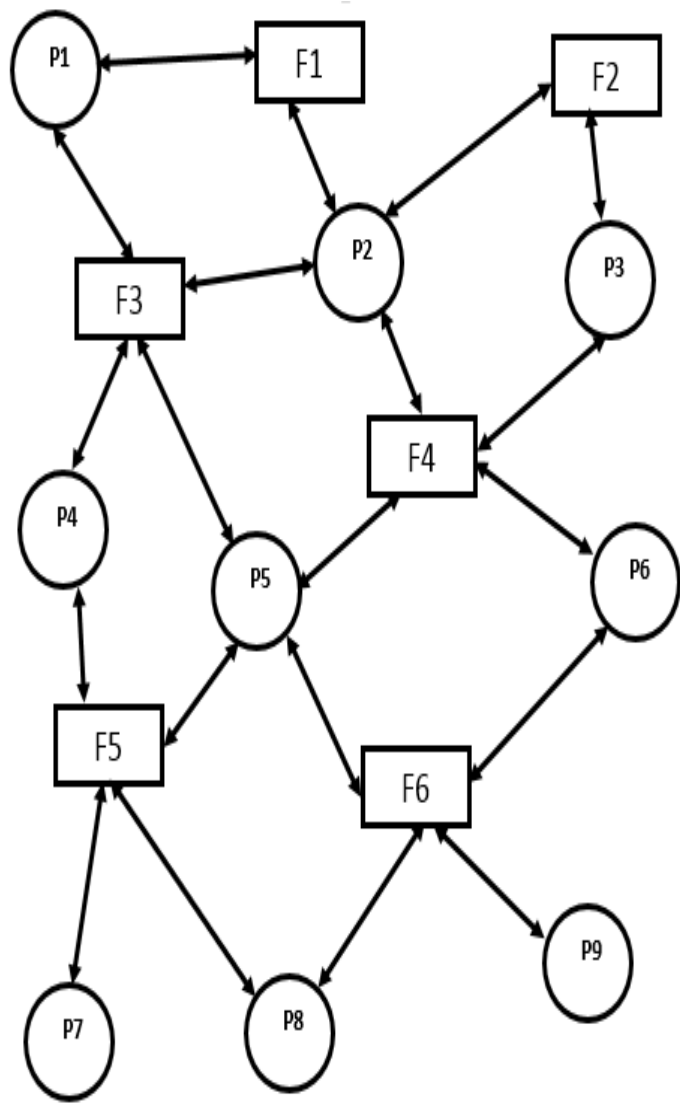

Figure 1: A Sample network characterizing the spatial orientation of an apiary

The circular nodes represent foraging plants, the rectangular nodes represent fields within the range of the beekeeper and the arrows denote that the foraging plants are located in the area of the maximum flight of the foragers from the connected fields. The network is used to guide the beekeeper on the best field to locate his beehives. Preference is given to the availability and richness of the nectars in a foraging plant as well as the distance of the foraging plant from the field. A beekeeper may have to abandon a field located close to a foraging plant with disease or beyond the flight strength of the foragers.

To determine the optimal distribution of beehives in the field using Figure 1, one needs to maximize the number of foraging plants connected to the fields with respect to parameters such as the priority weight of the fields, large number used as penalty weight and portion of bees in a field not accommodated by available nectar which must be subjected to some constraints. For instance, F1 and F3 are connected to P1; F2, F3 and F4 are connected to P2; F2 and F4 are connected to P3; F3 and F5 are connected to P 4; F 3; F4 and F5 are connected to P5; F4 and F6 are connected to P 6; F5 is connected to P7; F5 and F6 are connected to P8; F6 is connected to $\mathrm{P} 9$.

The following notations for the decision variables and parameters (Table 1) shall be used. Strength of a hive represents the number of bees in the hive and the labour capacity of a colony represents the number of labourers 
that can be deployed to a particular hive.

Let the decision variables:

$y_{i j}$ be the Portion of bees in the field $i$ that can be accommodated by foraging plants $\mathrm{j}, \mathrm{y}_{\mathrm{ij}} \in \mathrm{R}, L_{i}$ be the portion of bees in field $i$ that cannot be accommodated by the available foraging plants, $L_{i} \in \mathrm{R}$

$Z_{\text {ri }}=1$ if one or more hives are located to field $i$, otherwise 0 .

Table 1: Specified Parameters and Definition

\begin{tabular}{|c|c|}
\hline Parameter & Description \\
\hline $\mathrm{F}$ & total number of fields \\
\hline M & total number of hives \\
\hline Q & total number of forage plants \\
\hline $\mathrm{L}$ & required labour ability \\
\hline $\mathrm{S}_{\mathrm{c}}$ & cost of storage \\
\hline $\mathrm{C}$ & cost of tools \\
\hline $\mathrm{E}$ & cost of feed \\
\hline $\mathrm{H}_{\mathbf{r}}$ & strength of hive $r, h_{r} \in R$ \\
\hline $\mathrm{W}_{\mathbf{j}}$ & carrying capacity of forage plant $\mathbf{j}, w_{\mathbf{j}} \in R$ \\
\hline$\mu_{\mathbf{j}}$ & mean of $w_{j}$ \\
\hline$\Sigma_{\mathbf{j}}$ & standard deviation of $\mathrm{w}_{\mathbf{j}}$ \\
\hline $\mathrm{V}_{\mathrm{i}}$ & priority weight given to field $\mathrm{i}, \mathrm{v}_{\mathbf{i}} \in \mathrm{R}$ \\
\hline $\mathrm{N}$ & $\begin{array}{l}\text { large positive number applied as penalty } \\
\text { weight to minimize overcrowding }\end{array}$ \\
\hline $\mathrm{j} \in \mathrm{C}_{\mathbf{i}}$ & $\begin{array}{l}\text { denotes that forage plant } \mathrm{j} \text { is connected to } \\
\text { field } \mathrm{i}\end{array}$ \\
\hline $\mathrm{i} \in \mathrm{D}_{\mathbf{j}}$ & $\begin{array}{l}\text { denotes that field } i \text { is connected to forage } \\
\text { plant } j\end{array}$ \\
\hline$Y_{\mathbf{i j}}$ & $\begin{array}{l}\text { portion of bees in hive } i \text { that can be } \\
\text { accommodated by field } \mathbf{j}\end{array}$ \\
\hline $\mathrm{L}_{\mathrm{i}}$ & $\begin{array}{l}\text { portion of bees in field } i \text { that cannot be } \\
\text { accommodated by the available forage } \\
\text { plants }\end{array}$ \\
\hline
\end{tabular}

\section{CRISP DETERMINISTIC MIXED-INTEGER HONEY BEE PRODUCTIVITY MODEL}

Crisp deterministic mixed integer is an open standard process model that describes approaches used by data mining expert in many areas of application since any model that incorporates discrete phenomena requires the consideration of integer variable. Beekeepers sometimes encounter problems, such as slowdown in the rate of bee- product production due to the competition within the area where bee colonies are located. Thus, crisp deterministic mixed-integer honey bee productivity model was designed to minimize cost of keeping hives in terms of labour, feeding, storage and tools through proper distribution of beehives within the available fields.

Let $y_{i j}, \mathbf{j} \in c_{\mathbf{i}}$ be the total strength of all hives to be located to field $i$ that can be accommodated by available forage plants, and let the variable $\mathrm{L}_{\mathrm{i}}$ represent the amount of bees in field $i$ that cannot be accommodated by the available forage plants(i.e overcrowd at field i).

Then the problem is to

Maximize

$$
\sum_{i=1}^{f}\left(v_{i} \sum_{j \in C_{i}} y_{i j}-N L_{i}\right)
$$

Subject to

$$
\begin{aligned}
& \sum_{i \in D_{j}} y_{i j} \leq w_{j}, j=1,2, \ldots ., q \\
& \sum_{i=1}^{f} z_{r i}=1 r=1,2, \ldots ., m \\
& \sum_{r=1}^{m} h_{r} z_{r i}-\sum_{j \in C_{i}} y_{i j}-L_{i} \leq 0 \\
& \forall i=1,2, \ldots ., f
\end{aligned}
$$

The penalty weight $\mathrm{N}$ in (1) could be very large and could be greater than the beekeeper's desired weight $\mathrm{v}_{i}$, hence, the minimization of the overcrowd $\mathrm{L}_{\mathbf{i}}$ is paramount with regard to the maximization of the total strength of the hives at the beekeeper's disposal. The beekeeper needs to first maximize the hives with higher productivity tendency before considering the maximization of the ones with lower productivity tendency. The hives which has moderate feed consumption rate but optimal output is maximized. Equation (2) shows that the total number of bees accommodated by a forage plants $\mathbf{j}$ does not exceed the availability nectar in forage plant $\mathbf{j}$ while (3) shows that each bee hive has the exact feed required. The implication of (4) is that if hives are located at field $\mathrm{i}$ then the feeds connected to hive $\mathrm{r}$ are forced to accommodate all the strengths of these colonies. If the feed connected to a particular hive cannot accommodate all the strengths then overcrowd arises $\left(\mathrm{L}_{\mathrm{i}}\right.$ is forced to be greater than zero) on the other hand. Section III is divided into three subsections i, ii, and iii.

i. Data Collection

Real life data, Tables 2- 4 were obtained from a beekeeper in St. Benedictine Monastery, Ewu-Esan, Edo State, Nigeria. 
Table 2: Cost of maintaining the hives $(\operatorname{cost} \times 100)$

\begin{tabular}{|c|c|c|c|c|}
\hline Hives & labour & feed & storage & tools \\
\hline $\mathrm{h}_{1} 1$ & 30 & 20 & 50 & 45 \\
$\mathrm{~h}_{2}$ & 40 & 35 & 30 & 40 \\
$\mathrm{~h}_{3}$ & 20 & 40 & 35 & 30 \\
$\mathrm{~h} 4$ & 50 & 15 & 30 & 35 \\
\hline
\end{tabular}

Table 3: Strength of each hives

\begin{tabular}{|l|c|}
\hline & Strength $\times 10,000$ \\
\hline $\mathrm{h}_{1}$ & {$[2.1,3.1]$} \\
$\mathrm{h}_{2}$ & {$[0.9,1.9]$} \\
$\mathrm{h}_{3}$ & {$[3.2,4.2]$} \\
$\mathrm{h}_{4}$ & {$[0.5,1.5]$} \\
\hline
\end{tabular}

Table 4: Carrying capacity of forage plants $(\times 10,000)$

\begin{tabular}{|c|c|c|c|c|c|c|c|c|c|c|c|c|c|}
\hline & ${ }^{w} 1, \mathbf{j}$ & $w_{2, j}$ & w3,j & $\mathrm{w} 4, \mathrm{j}$ & w5,j & ${ }^{w} 6, j$ & $\mathrm{w} 7, \mathrm{j}$ & w8,j & w9,j & ${ }^{w} 10, j$ & $\mu_{\mathbf{j}}$ & $\sigma_{\mathbf{j}}$ & $\Phi_{j}^{-1}(0.1$ \\
\hline $\mathrm{fp}_{1}$ & 1.60 & 1.08 & 0.16 & 1.11 & 0.20 & 1.92 & 0.64 & 0.31 & 1.26 & 1.46 & 0.97 & 0.62 & 0.18 \\
\hline $\mathrm{fp}_{2}$ & 1.90 & 0.52 & 1.66 & 1.04 & 2.08 & 2.11 & 0.09 & 3.16 & 2.93 & 1.02 & 1.65 & 0.09 & 1.46 \\
\hline $\mathrm{fp}_{3}$ & 2.22 & 1.83 & 1.28 & 0.36 & 4.16 & 3.15 & 2.22 & 1.75 & 0.19 & 1.22 & 1.84 & 1.20 & 0.30 \\
\hline $\mathrm{fp} 4$ & 3.41 & 4.70 & 1.39 & 5.14 & 2.90 & 2.29 & 6.75 & 5.04 & 4.33 & 5.00 & 4.10 & 1.59 & 2.06 \\
\hline $\mathrm{fp} 5$ & 0.78 & 2.00 & 1.48 & 3.27 & 1.77 & 4.01 & 5.11 & 0.46 & 6.84 & 3.42 & 2.91 & 2.02 & 0.32 \\
\hline $\mathrm{fp}_{6}$ & 1.02 & 1.96 & 3.61 & 2.60 & 4.68 & 0.80 & 2.17 & 2.58 & 3.12 & 2.60 & 2.51 & 1.15 & 1.04 \\
\hline
\end{tabular}

The Carrying capacity of forage plants $(\times 10,000)$ values are obtained by determining the number of nectar and the number of foragers that can be accommodated by each nectar. The data obtained from an observation of 10 weeks carrying capacity. $f p_{\mathbf{j}}$ denotes forage plants $\mathbf{j}$ and $\mathrm{W}_{\mathbf{t} \mathbf{j}}$ denotes week $\mathrm{t}$ corresponding to $\mathrm{fp}_{\mathbf{j}}$.

Tables 3 and 4 , gives the values for parameters $\mu_{\mathbf{j}}, \sigma_{\mathbf{j}}$ and $\Phi^{-1}$ which is derived using Lingo 17.0 software, @PNORMINV(mu, sigma, x), where $\mu$ and $\sigma$ are mean and standard deviation of the carrying capacity.

\section{ii. The Weighted Sum Model}

The weighted sum model is commonly used in single dimensional problems if there are A alternatives (number of hives) and B criteria (costs) then, the best alternative is the one that satisfies (in the minimization case) the expression

$$
\begin{aligned}
& H_{W S M}=\min \sum_{j=1}^{B} h_{i j} v_{j} \\
& i=1,2, . ., A
\end{aligned}
$$

where $H_{W S M}$ is the weighted sum model(WSM ) result of the best alternative, $\mathrm{B}$ is the number of decision criteria, $h_{i j}$ is the actual value of the $i$ th alternative in terms of the $j$ th criterion and $v_{j}$ is the priority weight of the 
jth criterion.

The beekeeper matrix is stated as;

Criteria

\begin{tabular}{|c|c|c|c|}
\hline & $\mathrm{c}_{1}$ & $c_{2}$ & $\mathrm{c}_{3} \quad \ldots \mathrm{c}$ \\
\hline Hives & $\left(\mathrm{V}_{1}\right.$ & $\mathrm{V}_{2}$ & $\left.V_{3} \ldots V_{B}\right)$ \\
\hline $\mathrm{H}_{1}$ & $\mathrm{~h}_{11}$ & $\mathrm{~h}_{12}$ & $\mathrm{~h}_{13} . . \mathrm{h}_{1 \mathrm{~B}}$ \\
\hline $\mathrm{H}_{2}$ & $\mathrm{~h}_{21}$ & $\mathrm{~h}_{22}$ & $h_{23} . . h_{2 B}$ \\
\hline $\mathrm{H}_{3}$ & $\mathrm{~h}_{31}$ & h32 & $h_{33} . . h_{3 B}$ \\
\hline .. & . & ${ }^{\circ}$ & . \\
\hline $\mathrm{H}_{\mathrm{A}}$ & $\mathrm{h}_{\mathrm{A} 1}$ & $\mathrm{~h}_{\mathrm{A} 2}$ & $\mathrm{~h}_{\mathrm{A}} 3 \ldots \mathrm{h}_{\mathrm{AB}}$ \\
\hline
\end{tabular}

Minimum value of $\mathrm{H}_{\mathrm{i}}$ is obtained by equation (5).

iii. The Analytic Hierarchy Model (AHM)

In the case of complexity in decision making, Analytic Hierarchy Model according to [16] and [6] can be apply to decompose it into a system of hierarchies using A $\times \mathrm{B}$ (where $\mathrm{A}$ is the number of alternatives and $\mathrm{B}$ is the number of criteria). The AHM uses relative values instead of actual value and can be used in a single or multidimensional decision making problem.

Thus we have

$$
\begin{aligned}
& H_{A H M}=\min \sum_{j=1}^{B} h_{i j} v_{j}, \\
& i=1,2, \ldots, A
\end{aligned}
$$

\section{NUMERICAL IMPLICATION}

Numerical implications is presented in this section using real life data Tables 2-4 and the results were interpreted in section $\mathrm{V}$

\section{Problem 1}

A beekeeper has four costs (criteria), which were expressed in exactly the same unit and four hives (alternatives). If the priority weights of the four criteria were given as $v_{1}=0.35, v_{2}=0.25, v_{3}=0.10$, and $v_{4}=0.30$ (where $v_{i}$ is $\times 10,000$ ) and the corresponding $h_{i j}$ values are given as;

$$
H=\left[\begin{array}{llll}
30 & 20 & 50 & 45 \\
40 & 35 & 30 & 40 \\
20 & 40 & 35 & 30 \\
50 & 15 & 30 & 35
\end{array}\right]
$$

Find the best beehive to be chosen by the beekeeper in terms of cost optimization.

\section{Solution}

The matrix for the problem is;

Criteria

\begin{tabular}{ccccc} 
& $\mathrm{c}_{1}$ & $\mathrm{c}_{2}$ & $\mathrm{c}_{3}$ & $\mathrm{c} 4$ \\
Hives & $(0.35$ & 0.25 & 0.10 & $0.30)$ \\
\hline $\mathrm{H}_{1}$ & 30 & 20 & 50 & 45 \\
$\mathrm{H}_{2}$ & 40 & 35 & 30 & 40 \\
$\mathrm{H}_{3}$ & 20 & 40 & 35 & 30 \\
$\mathrm{H}_{4}$ & 50 & 15 & 30 & 35
\end{tabular}

By equation (5),

$\mathrm{H}_{1}=34, \mathrm{H}_{2}=37.75, \mathrm{H}_{3}=29.5, \mathrm{H}_{4}=34.75$

Since $\mathrm{H}_{3}<\mathrm{H}_{1}<\mathrm{H}_{4}<\mathrm{H}_{2}$, hence the best hive is hive 3 $\left(\mathrm{H}_{3}\right)$.

\section{Problem 2}

Determine the best beehive to be chosen by the beekeeper in terms of cost optimization if

the beekeeper has four costs (criteria) which were expressed in exactly the same unit and six hives (alternatives). The priority weights of the four criteria are given as $\mathrm{v}_{1}=0.15, \mathrm{v}_{2}=0.30, \mathrm{v}_{3}=0.20$, and $\mathrm{v}_{4}=$ 0.35 (where $\left.\mathrm{v}_{\mathrm{i}} \times 10,000\right)$ and the corresponding $\mathrm{h}_{\mathrm{ij}}$ values are;

$$
H=\left[\begin{array}{llll}
50 & 15 & 35 & 60 \\
45 & 20 & 30 & 50 \\
60 & 10 & 25 & 55 \\
45 & 15 & 40 & 60 \\
50 & 20 & 30 & 45 \\
55 & 10 & 35 & 45
\end{array}\right]
$$

\section{Solution}

The matrix for the problem is Criteria 
$\begin{array}{llll}\mathrm{c}_{1} & \mathrm{c}_{2} & \mathrm{c}_{3} & \mathrm{c}_{4}\end{array}$

Hives $\quad\left(\begin{array}{llll}0.15 & 0.30 & 0.20 & 0.35\end{array}\right)$

$\begin{array}{lllll}\mathrm{H}_{1} & 50 & 15 & 35 & 60 \\ \mathrm{H}_{2} & 45 & 20 & 30 & 50 \\ \mathrm{H}_{3} & 60 & 10 & 25 & 55 \\ \mathrm{H}_{4} & 45 & 15 & 40 & 60 \\ \mathrm{H}_{5} & 50 & 20 & 30 & 45 \\ \mathrm{H}_{6} & 55 & 10 & 35 & 45\end{array}$

By equation (5),

$\mathrm{H}_{1}=40, \mathrm{H}_{2}=49.75, \mathrm{H}_{3}=36.25, \mathrm{H}_{4}=40.25$,

$\mathrm{H}_{5}=35.25, \mathrm{H}_{6}=33.95$

Also, since $\mathrm{H}_{6}<\mathrm{H}_{5}<\mathrm{H}_{3}<\mathrm{H}_{1}<\mathrm{H}_{4}<\mathrm{H}_{2}$. Hence the best hive is $\mathrm{H}_{6}$.

\section{Problem 3}

Using the data in (Table 2) to obtain the priority weights $\left(\mathrm{v}_{i}\right)$ to be assigned to the fields where the beehives are to be located given the relative weights $\left(r w_{i}\right)$ of the four criteria as $r w_{1}=0.35, r w_{2}=0.25, r w_{3}=0.10, r w_{4}=0.30$

\section{Solution}

Let each entry in the matrix be divided by the summation value of that particular column. Thus,

\begin{tabular}{cccc}
$\mathrm{c}_{1}$ & $\mathrm{c}_{2}$ & $\mathrm{c}_{3}$ & $\mathrm{c}_{4}$ \\
$(0.35$ & 0.25 & 0.10 & $0.30)$ \\
\hline$\frac{30}{140}$ & $\frac{20}{110}$ & $\frac{50}{145}$ & $\frac{45}{150}$ \\
$\frac{40}{140}$ & $\frac{35}{110}$ & $\frac{30}{145}$ & $\frac{40}{150}$ \\
$\frac{20}{140}$ & $\frac{40}{110}$ & $\frac{35}{145}$ & $\frac{30}{150}$ \\
$\frac{50}{140}$ & $\frac{15}{110}$ & $\frac{30}{145}$ & $\frac{35}{150}$
\end{tabular}

By equation (6),

$\mathrm{H}_{1}=0.24, \mathrm{H}_{2}=0.28, \mathrm{H}_{3}=0.22, \mathrm{H}_{4}=0.26$

Thus, $\mathrm{v}_{\mathbf{i}}$ are; $\mathrm{v}_{1}=0.24, \mathrm{v}_{2}=0.28, \mathrm{v}_{3}=0.22, \mathrm{v}_{4}=0.26$.
Problem 4

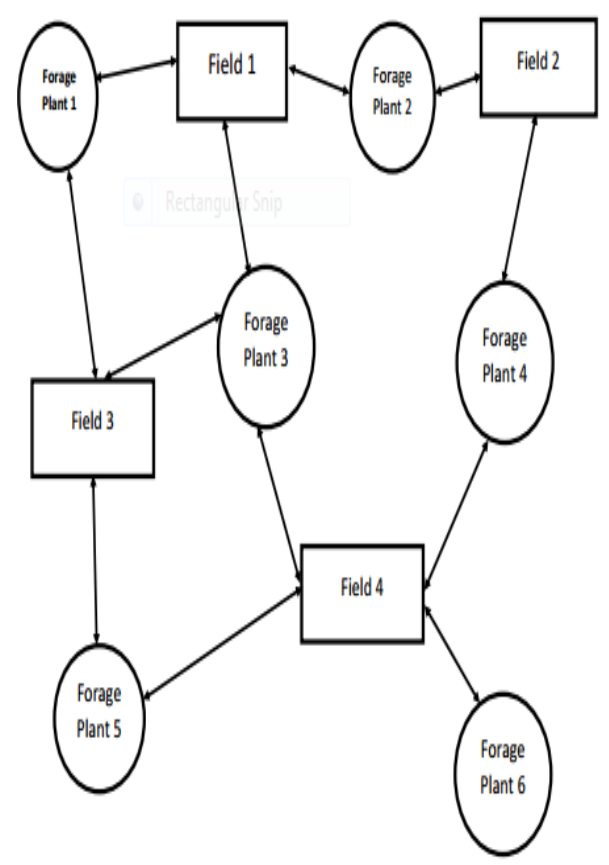

Figure 2: Network characterizing the spatial orientation of St. Benedictine Monastery apiary.

Use "Fig 2" to determine the fields where the beekeeper is to situate his beehives to optimize production and minimize overcrowd where the distance between two nodes is $\leq 650 \mathrm{~m}$, the priority weight $\mathrm{v}_{\mathbf{i}}$ are given as $\mathrm{v}_{1}=(0.24), \mathrm{v}_{2}=(0.28), \mathrm{v}_{3}=(0.22)$ and $\mathrm{v}_{4}=(0.26)$, $\mathrm{N}=1000$, the strength of each hive is in Tables 2-3 and the carrying capacity of each forage plant is given in Table 4 .

\section{Solution}

Using "Fig 2" to assign fields to the foraging plants the problem becomes;

$$
\begin{aligned}
& \text { Maximize } \\
& \quad 0.24\left(\mathrm{y}_{11}+\mathrm{y}_{12}+\mathrm{y}_{13}\right)+0.28\left(\mathrm{y}_{22}+\right. \\
& \left.\mathrm{y}_{24}\right)+0.27\left(\mathrm{y}_{3} 1+\mathrm{y}_{33}+\mathrm{y}_{35}\right)+ \\
& 0.26\left(\mathrm{y}_{43}+\mathrm{y}_{44}+\mathrm{y}_{45}+\mathrm{y}_{46}\right)- \\
& 1000\left(\mathrm{~L}_{1}+\mathrm{L}_{2}+\mathrm{L}_{3}+\mathrm{L}_{4}\right)
\end{aligned}
$$

Subject to

$$
\begin{aligned}
& \mathrm{y} 11+\mathrm{y} 31 \leq 0.18 \\
& \mathrm{y} 12+\mathrm{y} 22 \leq 1.46 \\
& \mathrm{y} 13+\mathrm{y} 33+\mathrm{y} 43 \leq 0.30 \\
& \mathrm{y} 24+\mathrm{y} 44 \leq 2.06
\end{aligned}
$$




$$
\begin{aligned}
& \mathrm{y} 35+\mathrm{y} 45 \leq 0.32 \\
& \mathrm{y} 46 \leq 1.04 \\
& \mathrm{z}_{11}+\mathrm{z}_{12}+\mathrm{z}_{13}+\mathrm{z}_{14}=1 \\
& \mathrm{z}_{21}+\mathrm{z}_{22}+\mathrm{z}_{23}+\mathrm{z}_{24}=1 \\
& \mathrm{z} 31+\mathrm{z} 32+\mathrm{z} 33+\mathrm{z} 34=1 \\
& \mathrm{z} 41+\mathrm{z} 42+\mathrm{z} 43+\mathrm{z} 44=1 \\
& 3.1 \mathrm{z}_{11}+1.9 \mathrm{z}_{21}+4.7 \mathrm{z}_{31}+1.5 \mathrm{z}_{4} 1 \\
& -\mathrm{y}_{11}-\mathrm{y}_{12}-\mathrm{y}_{13}-\mathrm{L}_{1} \leq 0 \\
& 3.1 \mathrm{z}_{12}+1.9 \mathrm{z}_{22}+4.7 \mathrm{z}_{32}+1.5 \mathrm{z} 42 \\
& -\mathrm{y}_{22}-\mathrm{y}_{24}-\mathrm{L}_{2} \leq 0 \\
& 3.1 \mathrm{z} 13+1.9 \mathrm{z} 23+4.7 \mathrm{z} 33+1.5 \mathrm{z} 43 \\
& -\mathrm{y} 31-\mathrm{y} 33-\mathrm{y} 35-\mathrm{L}_{3} \leq 0 \\
& 3.1 \mathrm{z} 14+1.9 \mathrm{z} 24+4.7 \mathrm{z} 34+1.5 \mathrm{z} 44 \\
& -\mathrm{y} 43-\mathrm{y} 44-\mathrm{y} 45-\mathrm{y} 46-\mathrm{L} 4 \leq 0
\end{aligned}
$$

Using mathematical program Lingo 17.0 software, the result is shown in Table 5
Table 5: Optimal solution obtained using Lingo 17.0

\begin{tabular}{|c|c|}
\hline Decision Variable & Optimal \\
\hline$y_{11}$ & 0.18 \\
$y_{22}$ & 1.46 \\
$y_{24}$ & 2.06 \\
$y_{43}$ & 0.30 \\
$y_{45}$ & 0.32 \\
$y_{46}$ & 1.04 \\
$y_{12}, y_{13}, y_{31}, y_{33}, y_{35}, y_{44}$ & 0 \\
$L_{1}$ & 5.34 \\
$L_{2}, L_{3}, L_{4}$ & 0 \\
$z_{12}$ & 0.46 \\
$z_{14}$ & 0.54 \\
$z_{22}, z_{41}$ & 1 \\
$z_{31}$ & 0.96 \\
$z_{32}$ & 0 \\
$z_{11}, z_{13}, z_{21}, z_{23}, z_{24}, z_{33}, z_{34}, z_{42}, z_{43}, z_{44}$ &
\end{tabular}

Table 5 shows that the beekeeper has to consider placing his beehives in fields1, 2 and 4 only.

\section{DISCUSSION OF RESULTS}

The result obtained shows that for optimal distribution of the beehives in other to optimize production and reduce overcrowding of foraging bees, the beekeeper should locate hives 3 and 4 at field 1 ; hive 2 at field 2 ; hive 1 at field 2 or 4. Furthermore the result shows that no hive should be located at field 3. The solution indicated that the estimated overcrowding is $5.34(\times 10,000)$ foragers, i.e $L_{1}+L_{2}+L_{3}+L_{4}=5.34$ where $\mathrm{L}_{2}, \mathrm{~L}_{3}$ and $\mathrm{L}_{4}=0$. Non satisfaction of equation (18) is as a result of overcrowding in field 1 which forced the foraging plants to accommodate the foraging bees. Field 3 is not assigned with any beehive due to inadequate nectars within the field location as well as far distance from the source of food which is outside the range of the maximum flight strength of honey bees. Thus the cost for production of honey is reduced with proper placement of bee- hives in the available fields in connection to the foraging plants as well as maximizes outputs of honey bee products as there 
is sufficient nectar and highly reduced competition among bees which often occur from overcrowding.

\section{CONCLUSION}

The major interest of any beekeeper is to enhance his honey production. Avoiding overcrowding of bees in the apiary which lead to competition for nectar among bees, absconding of bees or swarming from the bee farm are essential to guide against decline in the number of colonies of the beekeeper. In this paper Crisp deterministic mixed integer honey bee productivity model was formulated in an attempt to meet the interest of the beekeepers. The mathematical model formulated was solved using Lingo 17.0 software. And the results obtained shows that optimal spatial distribution of bee will maximize the production of honey and minimize the cost of production as well as overcrowding. In other words the adoption of this model by the beekeeper will increase the production of honey and consequently its availability for human consumption.

\section{REFERENCES}

[1] A. Abdullahi, J. Isekenegbe and U. S . Mohammed, Compar ative economic analysis of modern and traditional beekeeping in Lara and Zaria Local Government Area of Kaduna State, Nigeria. International Journal of Development and Sustainability. vol 3, no 5, 2014, pp. 989-999.

[2] S. A. Ahmad, A study of search neighbourhood in the bees algorithm. Ph.D Thesis, Cardiff University.Cardiff, 2012.

[3] Ama-Ogbari, C.C.O., Apiculture as an aspect of Nigeria's economic history. Knowledge Review. vol 30, no. 1, 2014, pp. 1-9.

[4] R. Amelia, N, Anggriani, and A. K. Supriatna, Optimal control model of Verticillium lecanii Application in the Spread of Yellow Red Chili Virus, WSEAS Transactions on Mathematics, Vol.18, 2019, pp.351-358

[5] M. I. Betti, L. M. Wahl, and M. Zamir, Effects of infection on honey bee population dynamics: a model. Journal of Public Library of Science One, vol 9, no 10, 2014, pp.110 237

[6] E. Bonabeau, M. Dorigo, and G. Theraulaz, Swarm intelligence: From natural to artificial system. Oxford University Press. New York. 1999

[7] M. Budiharjo, P. W. Agus, and M. Abulwafa, Comparison of Weighted Sum Model and Multi Attribute Decision Making Weighted Product Methods in Selecting the Best Elementary School in Indonesia. International Journal of Software Engineering and Its Applications. vol 11, no 4, 2017, pp. 69-90

[8] N. O. Dike and E. Onwuka, Entrepreneur perception and growth of bee-keeping in Abia State, Nigeria. International Journal of Physical and Human Geography, vol 4, no. 3, 2016, pp.1-11

[9] A. M. K. Gavina, F. J. Rabajante, and R. C. Cervancia, Mathematical programming models for determining the optimal location of beehives. Bulletin of Mathematical Biology, vol 7, no. 6, 2014, pp .997-1016.

[10] D. Karaboga and B.A. Basturk, Powerful and efficient algorithm for numerical function optimization: Artificial Bee Colony (ABC) algorithm. Journal of Global Optimization vol 9, no 3, 2007, pp. 459-491

[11] D. Karaboga and B.A. Basturk, On the performance of
Artificial Bee Colony(ABC) algorithm. Applied Soft Computing. vol.8, no. 1, 2008, pp. 687-697.

[12] N. Khan and W. Khan, Review of past literature of honey beekeeping and its production in rural area of the world. Food Science and Quality Management. vol.74, 2018, pp. 1823

[13] D. T. Pham, A. Ghanberzadeh, E. Kov, S. Otris, S. Rahim and M. Zaidi, The bees algorithm-A Novel tool complex optimization. Intel ligent Production Machines and Systems. vol. 2, 2006, pp. 454-459

[14] N. Quijano and K. M. Passino, Honey bee social foraging algorithms for resource allocation theory and application. American Control Conference, New York City, USA. 2007

[15] P. E. Ramon - Joseph, C. V. Michael, and F. R. Jomar, Determining the Optimal Distribution of Bee Colony Locations to Avoid Overpopulation Using Mixed Integer Programming. Journal of Nature Studies RM 224 (Annex), College of Science and Mathematics Building MSU-Iligan, Institute of Technology Andres Bonifacio Avenue, Tibanga,Iligan City. 2010

[16] D. Stephens and J. A. Stevens, Simple spatially explicit ideal-free distribution: a model and an experiment, Journal of Behavioural Ecology and Sociobiology. vol 49, 2001, pp.220 - 234.

[17] E. Triantaphyllou, Multi-criteria decision making methods: a comparative study. Springer Science and Business Media. vol 49, 2013, pp . 5-21

[18] B.Yuce, S. M. Packianather, E. Mastrocinque, D. T. Pham, and A. Lamiase, Honey bees inspired optimization: The bees algorithm. www.mdpi.com/journal/insects/ vol 4, 2013, pp. 646-662. 